\title{
High Temperature, Wireless Seismometer Sensor for Venus
}

\author{
George E. Ponchak ${ }^{1}$, Maximilian C. Scardelletti ${ }^{1}$, Brandt Taylor ${ }^{2}$, Steve Beard ${ }^{2}$, Roger D. Meredith ${ }^{1}$, \\ Glenn M. Beheim ${ }^{1}$, Gary W. Hunter ${ }^{1}$ and Walter S. Kiefer ${ }^{3}$ \\ 1. NASA Glenn Research Center, 21000 Brookpark Rd., Cleveland, OH 44135 USA
}

2. INPROX Technology Corporation, 60 State Street Suite 780, Boston, Ma 02109 USA

3. Lunar and Planetary Institute, 3600 Bay Area Blvd., Houston, Texas 77058

\begin{abstract}
Space agency mission plans state the need to measure the seismic activity on Venus. Because of the high temperature on Venus $\left(462^{\circ} \mathrm{C}\right.$ average surface temperature) and the difficulty in placing and wiring multiple sensors using robots, a high temperature, wireless sensor using a wide bandgap semiconductor is an attractive option. This paper presents the description and proof of concept measurements of a high temperature, wireless seismometer sensor for Venus. A variation in inductance of a coil caused by the movement of an aluminum probe held in the coil and attached to a balanced leaf-spring seismometer causes a variation of $\mathbf{7 0 0}$ $\mathrm{Hz}$ in the transmitted signal from the oscillator/sensor system at $426^{\circ} \mathrm{C}$. This result indicates that the concept may be used on Venus.
\end{abstract}

Index Terms - Wireless Sensor, Seismometer, oscillator, high temperature circuits.

\section{INTRODUCTION}

There is a strong demand among planetary scientists to understand the environment, geology, volcanic activity, and seismic events of Venus because it may provide insight into climate change and the result of climate change on Earth [1]-[3]. While some of these measurements may be made over a short time frame, understanding volcanic and seismic activity requires long term measurements. The most recent mission plan for Venus states that the seismometer must operate at least 117 Earth days, with 365 Earth days preferred [1]. Moreover, the mission plans state that a minimum of four seismometers operating in a system on the surface are required [1], [3]. Venus has a very hostile environment with an average surface temperature of $462^{\circ} \mathrm{C}$, an atmospheric pressure of $90 \mathrm{~atm}$ on the surface, and an atmosphere comprised primarily of $\mathrm{CO}_{2}$ [1]-[4]. To operate a seismometer at such high temperatures for a long time, the mission must use an active cooling system if Sibased electronics are used or else substitute wide bandgap electronics, such as $\mathrm{SiC}$ and $\mathrm{GaN}$, to eliminate the cooling system. Because the power requirements and weight of an active cooling system increase the mission costs, $\mathrm{SiC}$ electronics may be the better alternative if it can be shown to operate reliably for at least one year in the Venus environment. Wireless communication may be an asset, because it would allow the seismometer to be deployed at some distance from the parent spacecraft, partially decoupling the seismometer from oscillations created on the main spacecraft (Fig. 1).

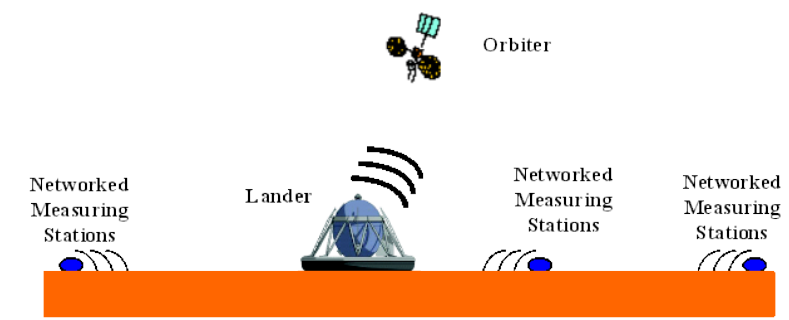

Figure 1: Artist drawing of seismometer system operating on Venus.

In this paper, a high temperature, wireless seismometer sensor is described and measurements to verify the proof of concept are presented. Section II presents a description of the seismometer, Section III presents the oscillator circuit with the integrated seismometer design, Section IV presents measurement setup, Section $\mathrm{V}$ presents the wireless seismometer sensor measured data, and Section VI presents conclusions.

\section{SEISMOMETER}

A seismic measurement device that functions over the range of $0.3 \mathrm{mHz}$ to $30 \mathrm{~Hz}$ and is operational to $500^{\circ} \mathrm{C}$ and pressures up to 90 bars is required. It is desired to approach or achieve sensitivity of $10^{-9} \mathrm{~m} \mathrm{sec}^{-2} \mathrm{~Hz}^{-1 / 2}$. A leaf-spring seismometer design is used [5]. This seismometer is a first generation prototype to demonstrate seismic sensing at extremely high temperatures. Further refinements, e.g. miniaturization and insertion in a vacuum chamber, will be required to produce a seismometer suitable for use on Venus. INPROX Technology has developed a high temperature variable spring tension seismometer utilizing a vertical pendulum design. A 
seismic mass is counterbalanced with a leaf spring by means of a boom that is supported by crossed hinges in the conventional way. A novel thermal expansion mechanism is employed to compensate for the change in Young's modulus experienced by the spring as temperature changes. Additionally, a variable inductor is employed as the transducer where the inductor will be used in the oscillator circuit. A specialized aluminum probe, mounted on the seismometer boom, is positioned on the inside of the inductor coil, and a change of axial position of the probe in the coil causes the inductance to change. Figure 2 shows the measured inductance as a function of the aluminum probe position and temperature. For this measurement, the counter-balance weight is set to lift the probe to its maximum height, and a ceramic rod attached to a micromanipulator is used to lower the aluminum probe in a controlled manner. An HP Impedance Analyzer is used to measure the inductance. Further description of the measurement setup is provided in Section IV.

The measured data shows that the inductance increases with temperature, but because the Venus surface temperature is thought to be relatively constant, the change in inductance with temperature should not affect the seismometer characteristics. The inductance varies as a function of the probe position, which is the desired characteristic. Because of thermal expansion of the components, the probe position is not absolute, but must be considered to be a relative position. At $23^{\circ} \mathrm{C}$ through $300^{\circ} \mathrm{C}$, the probe is at the top of the coil at approximately $4 \mathrm{~mm}$. At 400 and $426^{\circ} \mathrm{C}$, the probe is at the top of the coil at approximately 3 and $2 \mathrm{~mm}$, respectively. It is further seen that the inductance has a maximum value with a probe position at $8-10 \mathrm{~mm}$, depending on temperature, and the inductance decreases when the probe is pushed further down into the coil. Considering these limitations, the seismometer counter-weight should be adjusted so that the probe is positioned at $6 \mathrm{~mm}$ and allowed to move between 4 and $8 \mathrm{~mm}$, where the sensor has the highest sensitivity.

\section{OSCILLATOR DESIGN WITH INTEGRATED SEISMOMETER}

The oscillator is based on a Clapp-type design, and its schematic is shown in Fig. 3. Because the self-resonant frequency of the seismometer's coil is approximately 600 $\mathrm{kHz}$, the oscillator was designed to operate at $100 \mathrm{kHz}$. At this low frequency, antennas are typically large. Because small system size is important, a coil antenna comprised of 110 turns, a diameter of $16 \mathrm{~cm}$, and a measured inductance of $2.5 \mathrm{mH}$ at $100 \mathrm{kHz}$ is used. The antenna is placed in parallel with the sensor inductor, $\mathrm{L}_{-} \mathrm{T}$, and is part of the oscillator resonant circuit. The bias supplies were noisy and degraded the oscillator characteristics. Thus, bias-T's were used, as shown in Figure 3.

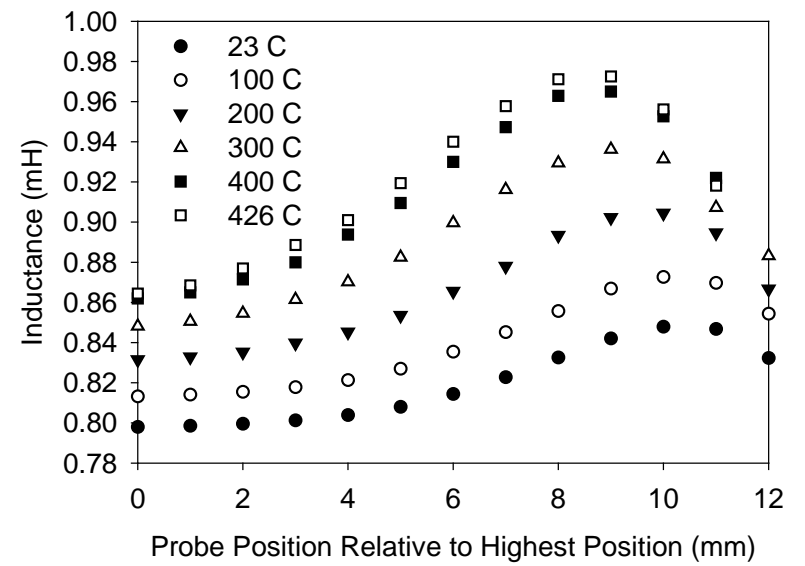

Figure 2: Measured inductance of the seismometer coil as a function of temperature and probe position.

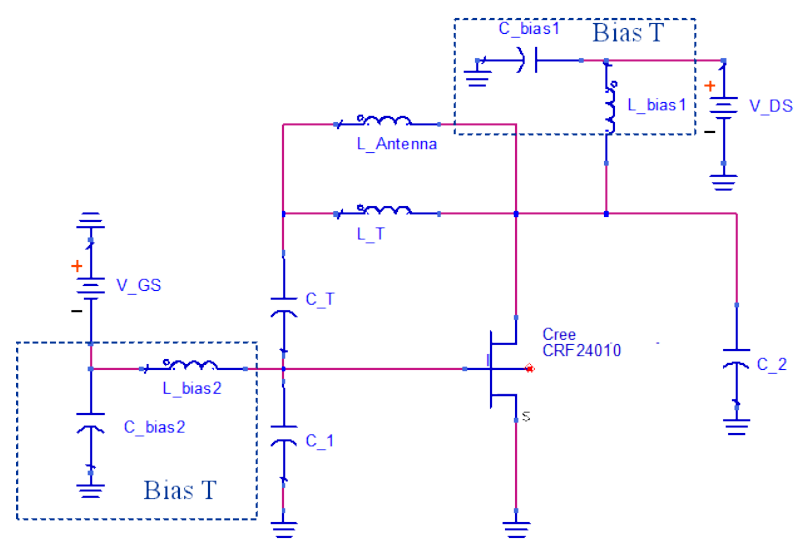

Figure 3: Schematic of wireless circuit for seismometer.

The oscillator uses a Cree CRF24010 SiC MESFET, and the capacitors C_1, C_2, and C_T are ceramic chip capacitors. These components are attached to an alumina substrate with electrically conductive epoxy, and $\mathrm{Au}$ wire bonds are used for connections. The element values are C_bias1 $=2.5 \mu \mathrm{F}$, C_bias2 $=2.5 \mu \mathrm{F}$, L_bias1 $=2.68 \mu \mathrm{mH}$, L_bias2 $=1.5 \mathrm{mH}, \mathrm{C} \_1=\mathrm{C} \_2=1800 \mathrm{pF}$, and C_T $=900 \mathrm{pF}$.

\section{SEISMOMETER MEASUREMENT SETUP}

High temperature testing of the wireless seismometer was performed in an oven. Because the inductive coil antenna cannot radiate from within the oven, it is placed outside the oven; it and the bias-T's are the only parts of the system that are not at the temperature of the test. The receive coil antenna is placed $1 \mathrm{~m}$ from the transmitting antenna. An Agilent spectrum analyzer is used to measure the received signal.

To minimize the effects of the oven fan and the vibrations from within the laboratory, a micromanipulator 
was used to adjust the boom position of the seismometer, as described in the previous section, in order to simulate a seismic event.

The oven temperature is controlled by the oven controller and maintains a temperature to within $1^{\circ} \mathrm{C}$. To verify the oven temperature, a thermocouple is placed in the oven and positioned in the center of the oven. The thermocouple and the oven temperature controller agreed to within $2^{\circ} \mathrm{C}$. A second thermocouple was placed on the brass plate to which the oscillator and seismometer were attached. Measurements were not made until the three thermocouples agreed to within $2^{\circ} \mathrm{C}$. Thus, the carrier temperature of the oscillator and the air temperature were at the same. Figure 4 shows photographs of the measurement setup inside the oven.

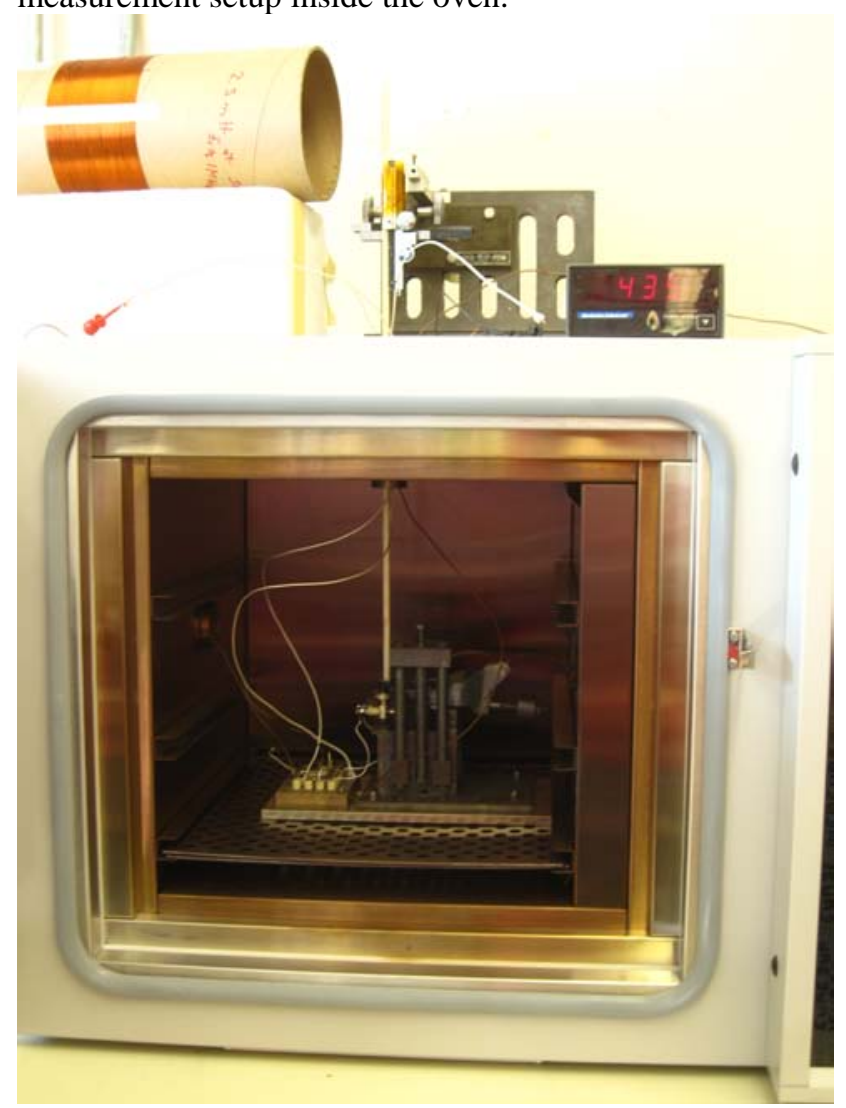

(a)

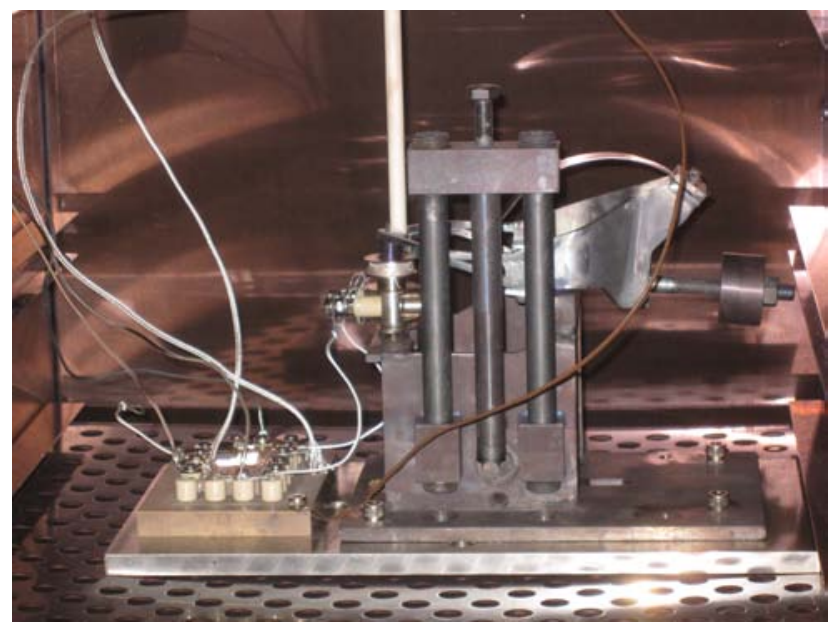

(b)

Figure 4 (a) and (b): Photographs of the wireless seismometer sensor test setup.

\section{WIRELESS SeISMOMETER SENSOR MEASUREd DATA}

Figure 5 shows the measured spectra of the signals received at the coil antenna as a function of probe position, with the seismometer at $426^{\circ} \mathrm{C}$ and a $1 \mathrm{~m}$ distance between transmitting and receiving antennas. As can be seen in Figure 5, the signal strength is $40 \mathrm{dBm}$ above the noise floor at $426^{\circ} \mathrm{C}$. At temperatures higher than $426^{\circ} \mathrm{C}$, the signal to noise ratio decreased and a valid measurement could not be made. The frequency of the signal as a function of probe position is shown in Fig. 6 for seismometer temperatures of 400 and $426^{\circ} \mathrm{C}$. Comparing Fig. 6 with Fig. 2, it is seen that the variation in signal frequency is directly related to the variation in the sensor coil inductance, with a minimum signal frequency at $9 \mathrm{~mm}$ probe height, the position of maximum inductance. At $400^{\circ} \mathrm{C}$, the total variation of signal frequency is approximately $340 \mathrm{~Hz}$, and the variation over the probe position of 4 to $8 \mathrm{~mm}$ is $240 \mathrm{~Hz}$. At $426^{\circ} \mathrm{C}$, the total variation of the signal frequency is approximately $700 \mathrm{~Hz}$, and the variation over the useful range of 4 to $8 \mathrm{~mm}$ is 450 $\mathrm{Hz}$. The trend of greater variation of signal frequency as a function of probe position with increasing temperature was seen over the entire temperature range of 100 to $426^{\circ} \mathrm{C}$. This follows the trend seen in Fig. 2 with greater variation in inductance with increased temperature. 


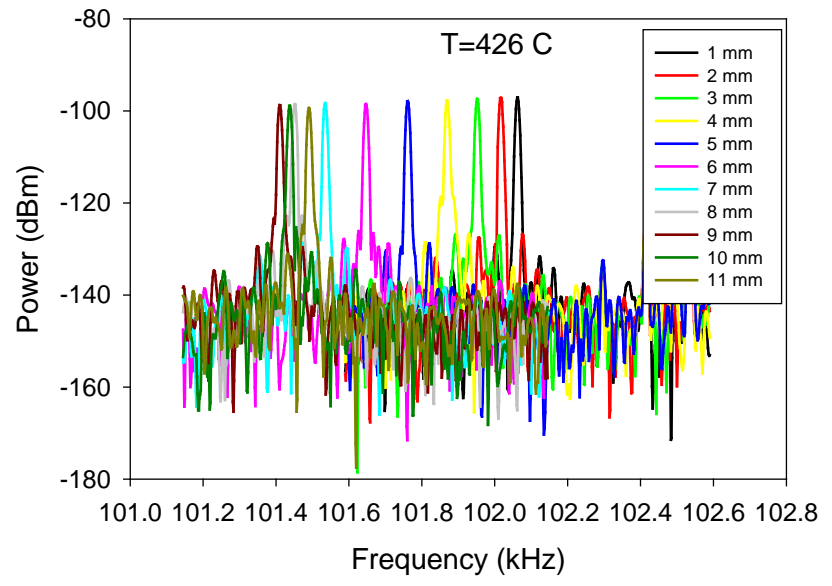

Figure 5: Measured spectra of the received signal from the wireless seismometer sensor for probe positions from 1 to $11 \mathrm{~mm}$, at $426^{\circ} \mathrm{C}$.

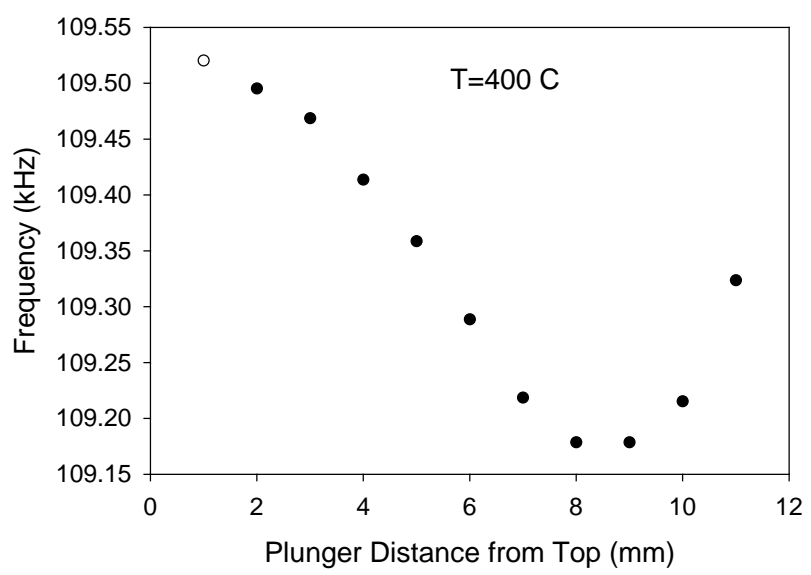

(a)

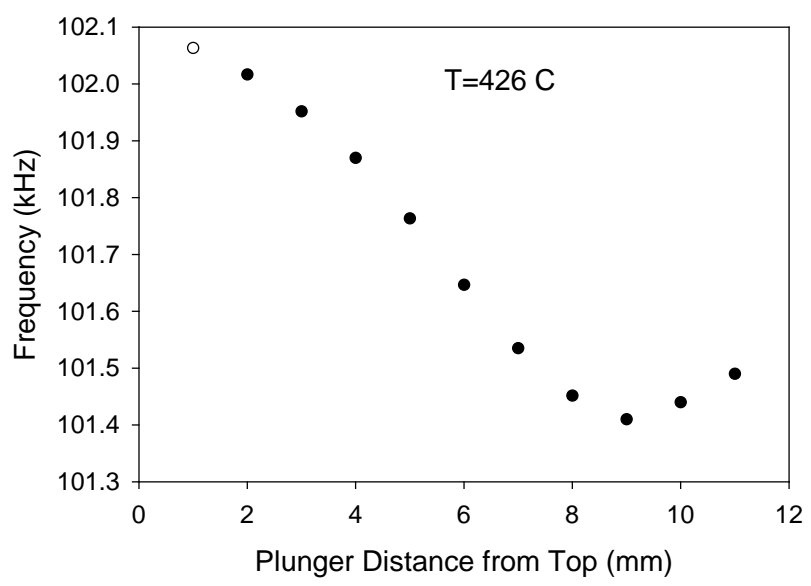

(b)

Figure 6: Measured frequency of the received signal from the wireless seismometer sensor as a function of probe position at (a) $400^{\circ} \mathrm{C}$, and (b) $426^{\circ} \mathrm{C}$.

\section{CONCLUSION}

This paper has presented a proof-of-concept design of a high temperature, wireless seismometer sensor for Venus. The oscillator with the integrated seismometer sensor operated well through $426^{\circ} \mathrm{C}$, but decreased signal to noise ratio did not allow operation through the required temperature. The high temperature, wireless sensor operated above $400^{\circ} \mathrm{C}$ for 4 hours, and it was still working when the test ended. However, long-term life tests are required to confirm the reliability for use on Venus. To improve the design, the radiating coil antenna should be removed from the oscillator feedback path to decrease its effects on the oscillator, and an amplifier should be included to increase the signal level to allow for higher temperature operation. A different antenna should be used to improve the radiation efficiency. Lastly, it must be noted that this was a very controlled experiment to verify the concept of the leaf-spring seismometer and the oscillator, and future experiments must be performed with the leaf-spring balanced at the optimum probe position and the experiment conducted in a facility that shakes the oven, and the seismometer, on a single axis in a controlled way.

\section{ACKNOWLEDGEMENT}

This project was funded through the NASA Planetary Instrument Definition and Development Program (PIDDP).

\section{REFERENCES}

[1] Final Report of the Venus Science and Technology Definition Team, Venus Flagship Mission Study, NASA, Jet Propulsion Laboratory, April 17, 2009.

[2] O. B. Khavroshkin, V. V. Tsyplakov, and L. Zasova, "The geophysical research program for Venus landing station," European Planetary Science Congress 2009, Potsdam, Germany 14-18 Sept. 14-18, 2009.

[3] G. A. Landis, "Robotic exploration of the surface and atmosphere of Venus,” Acta Astronautic, Vol. 59, Issue 7, Oct. 2006, pp. 570-579.

[4] J. S. Lewis, "An estimate of the surface conditions of Venus,” Icarus, Vol. 8, Issues 1-3, 1968, pp. 434-456.

[5] E. Wielandt and G. Streckeisen, "The leaf-spring seismometer: design and performance," Bulletin of the Seismological Society of America, Vol. 72, No. 6A, Dec. 1982 ,

$2349-2367$. 